\title{
An Improved of Inputs Scaling Factor Tuning Method Fuzzy Logic Speed Controller for Induction Motor Drive
}

\author{
M.H.N.Talib ${ }^{1}$, Z.Ibrahim ${ }^{1}$, Nabil Farah ${ }^{1}$, Z.Rasin ${ }^{1}$, J.M.Lazi ${ }^{1}$ and M.Azri ${ }^{1}$ \\ ${ }^{1}$ Faculty of Electrical Engineering, Universiti Teknikal Malaysia Melaka
}

\begin{abstract}
This paper proposes an improved of input scaling factor tuning method for the Fuzzy Logic Speed Controller (FLSC) of Induction Motor drive. The maximum gain of input scaling factor, FLSC is generally limited by the coverage of universe of discoursed $(U o D)$. Thus, to further increase the input gain scaling factor, $G_{e}$ the outer membership function need to be increased. This analysis covers various $G_{e}$ in the range of UoD values from [-1,1] to [-5,5] for rated speed operation. The FLSC is employed to the indirect Field Oriented Control method fed by a voltage source inverter. Simulation and experimental verification is done by using Matlab/Simulink and dSPACE 1103 controller experimental rigs respectively. Based on the results, speed performance behaviours are improved in term of rise time and setting time. The tuning approached is simple without additional algorithm for faster and more accurate response
\end{abstract}

Keywords: Induction Motor Drive, FLC, Simplified Rule, Speed Controller, Scaling Factor

\section{Introduction}

The popularity of the Fuzzy Logic Controller (FLC) is increased because of its ability to handle non linearity, disturbances and improved robustness [1-4]. The tuning of the controller however involves various parameters such as scaling factors (SF), membership function (MF) and decision rules. In fact, tuning of FLC is more complicated compared to the conventional PI controller due to many parameters involved [5,6]. A change in one of these parameters can significantly affect the overall performance [7, 8]. Among these parameters, tuning the SFs has the highest priority in the tuning of the FLC effectiveness and greatly influences the FLC performance $[7,9]$. However, there is no standard of tuning procedures for FLSC scheme like PI controllers.

In most cases, the scaling factor gains are tuned based on the normalized value of the universe of discourse (UoD) $[1,10,11]$. Under normalized value the universe of discourse (UoD) range is commonly set at $[-1,1]$. Thus, the maximum input gain scaling factor, $\mathrm{G}_{\mathrm{e}}$ is relatively small and limited based on this condition. As a result, fast speed response cannot be obtained. Majority of the previous research work, the optimum performance is achieved by tuning the MF parameters. Tuning the MFs mainly involves in adjusting the type, shape, nonlinearity and distribution of MFs [8, 10]. In addition, the analysis is limited only at the rated speed range operation. No details analysis discussed on the wide speed range operation or the behavior of the speed controller performance.

Some of the previous researchers also applied different range of UoD for the speed error such as more than [-1,1] of UoD [12-15]. However, the discussions of the selected range and the input variable or fuzzy subsets distribution are not discovered. Ming et all also applied higher range of UoD for speed error [16]. The maximum range is set at $[-6,6]$ determined based on the maximum speed of the motor. The fuzzy subsets distributions of the input variable are equally distributed with symmetrical and 50\% overlapping rate. However, this combination is believed to produce similar performance results with normalized UoD by adjusting the input 
scaling factor gain. In addition, there is no detail study on the inputs scaling factor tuning effect over a bigger range of UoD. From this hypothesis, the study of influence of the inputs scaling factor is conducted.

This paper investigates the influence of inputs scaling factor and universe of discourse (UoD) towards the speed performance in wide speed range operations. The UoD covers from $[-1,1]$ to $[-5,5]$ domain. The influences of the inputs gain variation are then investigated under rated and wide speed range operations. Simulation and experimental results are presented to validate the performance effects. The proposed input scaling tuning method has shown better controlling ability during transient and steady state performance.

\section{Induction Motor Drive}

The block diagram of the FLSC with indirect field oriented control of induction motor drive is shown in Figure 1. The drive system consists of induction motor, coordinate transformation, voltage source inverter, current controllers and speed controller.

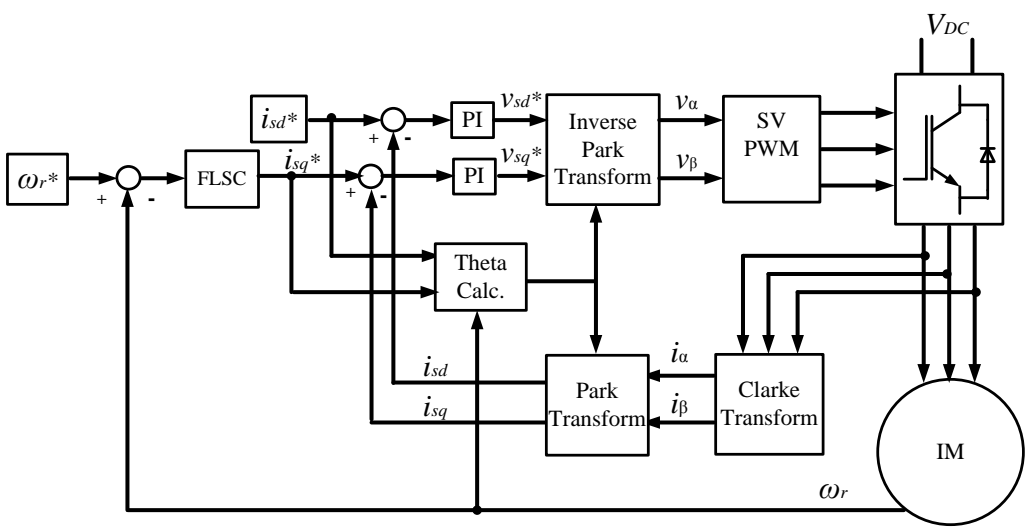

Fig 1: FLSC with indirect FOC method block diagram

The mathematical model of the three phase induction motor in synchronous reference frame is given in [17]. The voltage source inverter is controlled by mean of the Space Vector Pulse Width Modulation (SVPWM) method. Based on the indirect FOC principle, the rotor flux angle, $\theta_{\mathrm{e}}$ for coordinate transformation is generated from the integration of rotor speed, $\omega_{\mathrm{r}}$ and slip frequency, $\omega_{\mathrm{sl}}$ as shown in Equation (1).

$$
\theta_{e}=\int\left(\omega_{r}+\omega_{s l}\right) d t
$$

The slip frequency is calculate by using equation (2) below and included in theta calculation block.

$$
\omega_{s l}=\frac{L_{m}}{\tau_{r}} \frac{i_{s q}}{\varphi_{r}}
$$

The error between reference rotor speed, $\omega_{\mathrm{r}}^{*}$ and actual rotor speed, $\omega_{\mathrm{r}}$ is processed in the FLSC. The controller generates the $q$ axis reference current, $i_{s q}^{*}$. Meanwhile, a constant $d$ axis reference current, $i_{s d}^{*}$ is set for the input reference. Both $\mathrm{d}$-axis and q-axis stator current error are then regulated by the proportion integral (PI) controllers. These PI parameters are kept consistence in order to analysis the FLSC performance.

\section{FLSC Structure}

In general, a standard block diagram of the FLSC structure is shown in Figure 2. The controller consists of pre-processing, FLC and post-processing. 


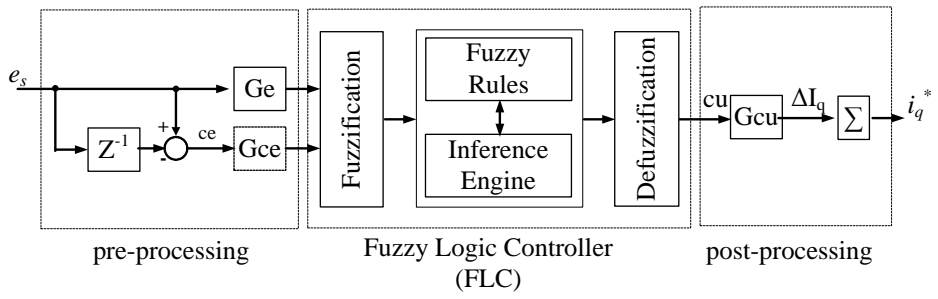

Fig 2: Standard FLSC block diagram

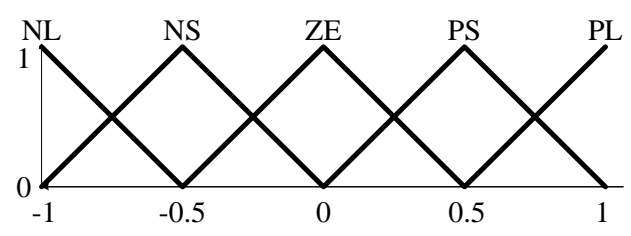

Fig 3: 5x5 MFs for e, ce and cu

The Mamdani system FLC structure has four main components that are fuzzification interface, fuzzy rules, inference engine and defuzzification interface. For the standard PI like FLC configuration, two input variables are used for speed error and change of speed error; and one output variable is changed at the output control. In pre-processing part, two fuzzy inputs variable for the controller are computed as presented by equation (3).

$$
\begin{gathered}
e(k)=G_{e}\left(\omega_{r}^{*}(k)-\omega_{r}(k)\right)=G_{e}(k) \\
\Delta e(k)=G_{c e} \frac{(e(k)-e(k-1))}{T_{s}}
\end{gathered}
$$

The inputs scaling factors $(\mathrm{SF}), \mathrm{G}_{\mathrm{e}}$ and $\mathrm{G}_{\mathrm{ce}}$ are the gain for speed error and change of speed error respectively. Meanwhile, $\omega_{\mathrm{r}}^{*}$ and $\omega_{\mathrm{r}}$ represent the reference and actual motor speed respectively. Indices $(\mathrm{k})$ and (k-1) represent the current and previous state of the system respectively to obtain the change of speed error, ce based on the sampling time $\mathrm{T}_{\mathrm{s}}$.

In this paper, 5x5 MFs matrixes are used for error, change of error and output incremental variables as shown in Figure 3. The symmetrical triangles are equally distributed with $50 \%$ overlap between the adjacent MFs. The inputs and output variables are normalized in [-1,1] domain. The MFs are named as Negative Large (NL), Negative Small (NS), Zero Error (ZE), Positive Small (PS) and Positive Large (PL).

In order to achieve high sampling rate for the real time implementation, the number of rules need to be reduced. Simplified rules method is performed to the 5x5 MFs rules based matrix as discussed in [18]. Based on the simplified rules method, only 7 rules are chosen out of the 25 rules. Through the simplification process, the computational time is reduced and the speed performance does not degraded. Figure 4 shows the 5x5 MFs rules matrix and selected simplified 7 rules. Figure 5 shows the MFs distribution to increase the UoD of the speed error.

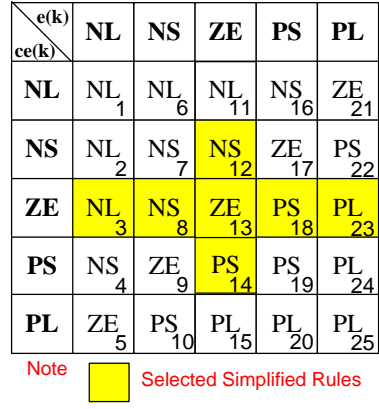

(a) $5 \times 5$ MFs rules matrix

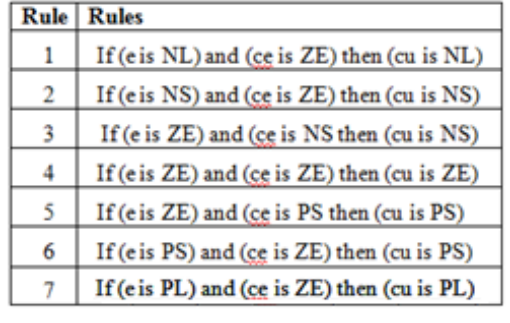

(b)Selected 7 rules

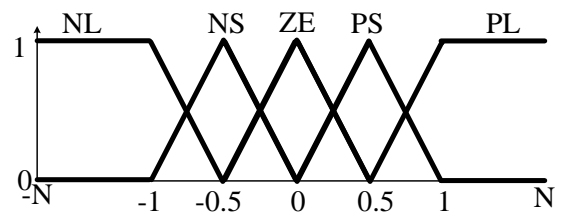

Fig 5 Modified MFs distribution for $\mathrm{N}$ multiplication factor of speed error SF

Fig 4. Selected rules for simplified FLSC

For the post-processing part, the incremental of output control, $\Delta \mathrm{i}_{\mathrm{q}}^{*}$ is compute by using center of gravity (COG) algorithm. The final output current signal demand, $\mathrm{i}_{\mathrm{q}}^{*}$ can be obtained by multiplying the $\Delta \mathrm{i}_{\mathrm{q}}^{*}$ with the output scaling factor, Gcu as written in equation (4):

$$
i_{q}^{*}(k)=i_{q}^{*}(k-1)+G_{c u}\left(\Delta i_{q}^{*}(k)\right)
$$




\section{Result and Discussion}

Several tests are conducted to investigate the performance of the speed under the proposed of inputs scaling factor tuning method. Three phase squirrel cage induction motor, $1.5 \mathrm{~kW}, 380 \mathrm{~V}$ used in this work and the parameters are $\mathrm{R}_{\mathrm{S}}=3.45 \Omega, \mathrm{R}_{\mathrm{r}}=3.6141 \Omega, \mathrm{L}_{\mathrm{s}}=0.3252 \mathrm{H}, \mathrm{L}_{\mathrm{r}}=0.3252 \mathrm{H}, \mathrm{L}_{\mathrm{m}}=0.3117 \mathrm{H}$ and J $=0.02 \mathrm{kgm}^{2}$. Simulation study of induction motor drive performance is implemented in MATLAB/Simulink software. The simulation results are then validated by using induction motor drive experimental rig by using dSAPCE 1103 controller. Figure 6 shows the hardware experimental setup for the drive system. The simulation and experimental parameters are set to be the same. Switching frequency of $8 \mathrm{kHz}$ is used for the space vector PWM. The overall sampling time is $50 \mu \mathrm{s}$.

\subsection{Operation under no-load condition}

The variation of input scaling factor controller are named from $S 7(\mathrm{UoD} \pm 1)$ to $S 7(\mathrm{UoD} \pm 5)$, representing the multiple of $G_{e}$ scaling factor from 1 to 5 . The $G_{c e}$ is tuned accordingly to achieve $100 \mathrm{rpm}$ design criteria at rated speed operation.

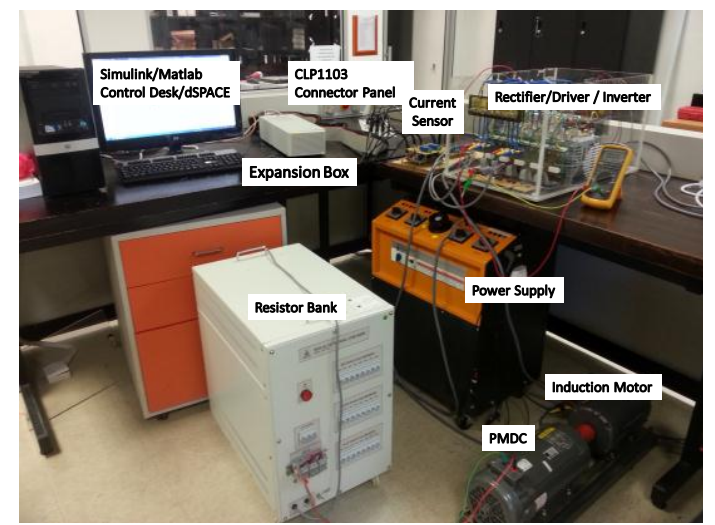

Fig 6 Hardware Experimental Setup

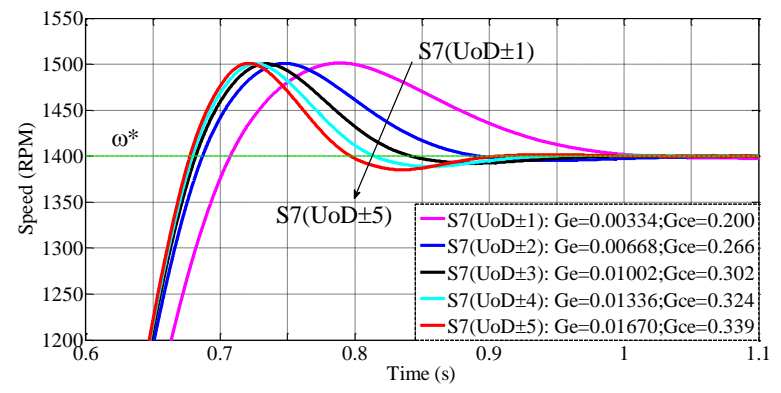

Fig 7 Speed response for different values of inputs SFs at rated no load speed operations

Figure 7 shows the close up view of simulation results from standstill to rated speed reference based on various inputs SF controllers at no load operation. The simulation is conducted in $2 \mathrm{~s}$ and the step speed demand is applied at $0.5 \mathrm{~s}$ from zero to rated $1400 \mathrm{rpm}$. Based on the results, $\mathrm{S} 7(\mathrm{UoD} \pm 5)$ produces faster rise time response and $S 7(\mathrm{UoD} \pm 1)$ results in slowest rise time response with $0.1775 \mathrm{~s}$ and $0.2074 \mathrm{~s}$ respectively. Further increase of inputs gain over 5 multiplications however results in slower impact of rise time and settling time. For example, the rise time improves to $0.0206 \mathrm{~s}$ between $\mathrm{S} 7(\mathrm{UoD} \pm 1)$ and $\mathrm{S} 7(\mathrm{UoD} \pm 2)$. Meanwhile, the rise time improves only $0.0018 \mathrm{~s}$ between $\mathrm{S} 7(\mathrm{UoD} \pm 4)$ and $\mathrm{S} 7(\mathrm{UoD} \pm 5)$. The higher inputs SFs also results in the increase of the underdamped situation. For example, the underdamped for $\mathrm{S} 7(\mathrm{UoD} \pm 5)$ is $15 \mathrm{rpm}$ and $\mathrm{S} 7(\mathrm{UoD} \pm 1)$ is $11 \mathrm{rpm}$. Thus, further increase of inputs scaling factors consequently results in the oscillation speed performance that may increase the settling time.

Simulation and experiment results are compared to understand the speed and currents behavior of the motor drive. Figure 8 shows the experiment and simulation results comparison for $S 7(\mathrm{UoD} \pm 1)$ and $S 7(\mathrm{UoD} \pm 5)$ respectively. Both simulation and experiment shows a good agreement. The experiment results however shows slower response with $0.037 \mathrm{~s}$ towards the rated speed due to the encoder linearity or dynamic inertia. 


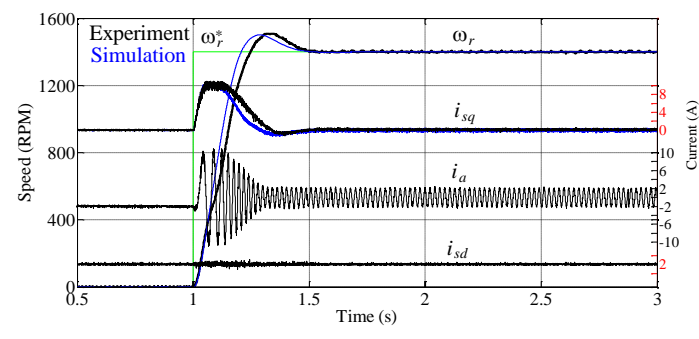

(a) $\mathrm{S} 7(\mathrm{UoD} \pm 1)$

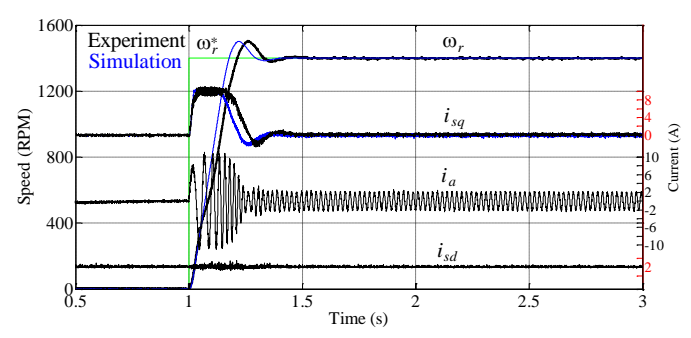

(b) $\mathrm{S} 7(\mathrm{UoD} \pm 5)$

Fig 8 Speed performance results during no load condition at 1400rpm

TABLE I: Error! Reference source not found.

\begin{tabular}{|c|c|c|c|}
\hline Controller & OS (\%) & Tr (s) & Ts (s) \\
\hline S7(UoD $\pm \mathbf{1})$ & 7.79 & 0.208 & 0.499 \\
\hline S7(UoD $\pm \mathbf{5})$ & 7.43 & 0.186 & 0.331 \\
\hline
\end{tabular}

\subsection{Operation under load condition}

Further performance investigation is carried out during loaded operation. The motor was initially operated at rated speed of no load condition until $2 \mathrm{~s}$ before a sudden rated load is applied. Figure 9 depicts the simulation and experimental results for the load rejection performance. Almost similar behaviors between simulation and experiment results are obtained for both controllers. However, the simulation result exhibits shorter recovery time due to smooth speed drop compared to the experiment result. The experiment results experiences distortion response at the undershoot region. This distortion is due to the additional mechanical coupling effect and measurement noise in the real setup.

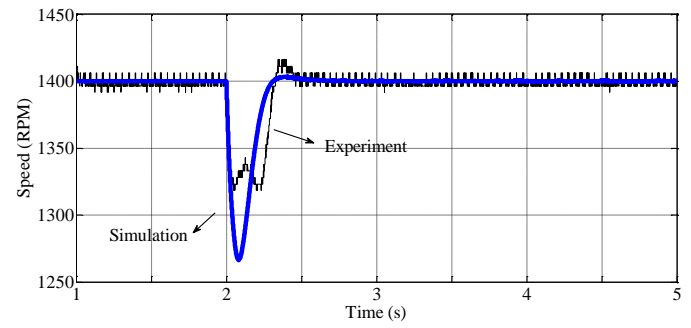

(a) $\mathrm{S} 7(\mathrm{UoD} \pm 1)$

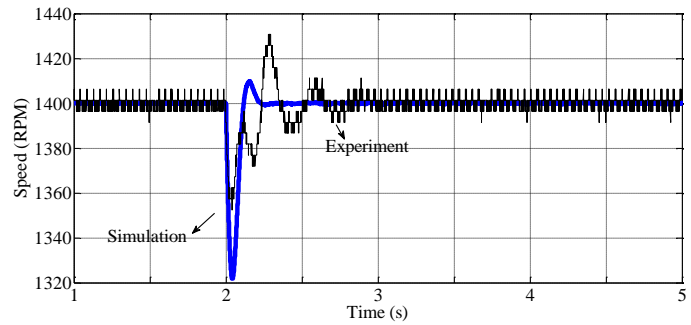

(b) $\mathrm{S} 7(\mathrm{UoD} \pm 5)$

Fig 9 Speed performance results during rated loaded condition at 1400rpm

Table 2 above records the performance comparison between the controllers for simulation and experiment. Based on the result, $\mathrm{S} 7(\mathrm{UoD} \pm 5)$ controller leads the motor performance with lowest speed drop and fastest sampling time. From the experiment result, $3.35 \%$ and $5.86 \%$ speed drop are recorded for the $\mathrm{S} 7(\mathrm{UoD} \pm 5)$ and $\mathrm{S} 7(\mathrm{UoD} \pm 1)$ respectively.

TABLE II: Performance comparison between controllers during load disturbance operations

\begin{tabular}{|c|c|c|c|}
\hline Controller & Test & Speed drop (RPM) & Recover Time (s) \\
\hline S7(UoD $\pm \mathbf{1})$ & Simulation & $78 \mathrm{rpm}$ & $0.116 \mathrm{~s}$ \\
\hline S7(UoD $\pm \mathbf{1})$ & Experiment & $47 \mathrm{rpm}$ & $0.235 \mathrm{~s}$ \\
\hline S7(UoD $\pm \mathbf{5}$ & Simulation & $133 \mathrm{rpm}$ & $0.309 \mathrm{~s}$ \\
\hline S7(UoD $\pm \mathbf{5})$ & Experiment & $82 \mathrm{rpm}$ & $0.329 \mathrm{~s}$ \\
\hline
\end{tabular}

\section{Conclusion}

This paper presents an improved method of input scaling factor tuning. Based on this method, the increment of $G_{e}$ value is proportionally requires an increment of the $\mathrm{UoD}$ ranges. Thus, the new maximum $\mathrm{G}_{\mathrm{e}}$ value can be obtained. No load and full load test are carried out to evaluate the influence of proposed inputs SF FLSC towards the motor drive performance. The analysis revealed that the increasing of input SF gain is able to produce faster rise time, settling time, smaller speed drop and shorter recovery time. The optimum performance is nearly 
achieved. Further increase of the gains however is limited by the undershoot condition and has less significant impact to the performance.

\section{Acknowledgment}

The authors would like to acknowledge their gratitude to the Universiti Teknikal Malaysia Melaka (UTeM) and the Ministry of Higher Education Malaysia under the research grant number FRGS/1/2015/TK04/FKE/02/F00258.

\section{References}

[1] A. Saghafinia, P. Hew Wooi, M. N. Uddin, and K. S. Gaeid, "Adaptive Fuzzy Sliding-Mode Control Into ChatteringFree IM Drive," IEEE Transactions on Industry Applications, vol. 51, no. 51, pp. 692-701, 2015. https://doi.org/10.1109/TIA.2014.2328711

[2] M. N. Uddin and J. Khastoo, "Fuzzy Logic-Based Efficiency Optimization and High Dynamic Performance of IPMSM Drive System in Both Transient and Steady-State Conditions," IEEE Transactions on Industry Applications, vol. 50, no. 50, pp. 4251-4259, 2014. https://doi.org/10.1109/TIA.2014.2317845

[3] Y.-K. Lu, "Adaptive Fuzzy Integral Sliding-Mode Regulator for Induction Motor Using Nonlinear Sliding Surface," International Journal of Power Electronics and Drive Systems, vol. 5, no. 5, p. 512, 2015. https://doi.org/10.11591/ijpeds.v5.i4.pp512-519

[4] M. S. Zaky and M. K. Metwaly, "A Performance Investigation of a Four-Switch Three-Phase Inverter-Fed IM Drives at Low Speeds Using Fuzzy Logic and PI Controllers," IEEE Transactions on Power Electronics, vol. 32, no. 32, pp. 3741-3753, 2017.

https://doi.org/10.1109/TPEL.2016.2583660

[5] L. Zheng, "A Practical Guide to Tune of Proportional and Integral (PI) like Fuzzy Controllers," in IEEE International Conference on Fuzzy Systems, 1992, pp. 633-640.

https://doi.org/10.1109/FUZZY.1992.258734

[6] F. Cupertino, A. Lattanzi, and L. Salvatore, "A New Fuzzy Logic Based Controller Design Method for DC and AC Impressed Voltage Drives," IEEE Transactions on Power Electronics, vol. 15, no. 15, pp. 974-982, Nov. 2000. https://doi.org/10.1109/63.892702

[7] W. Shun-Chung and L. Yi-Hua, "A Modified PI-Like Fuzzy Logic Controller for Switched Reluctance Motor Drives," IEEE Transactions on Industrial Electronics, vol. 58, no. 58, pp. 1812-1825, 2011.

[8] A. Lokriti, I. Salhi, S. Doubabi, and Y. Zidani, "Induction Motor Speed Drive Improvement using Fuzzy IP Self Tuning Controller: A Real Time Implementation," ISA Transactions, vol. 52, no. 52, pp. 406-417, May 2013. https://doi.org/10.1016/j.isatra.2012.11.002

[9] W. Yi, D. Huiwen, and C. Zheng, "Adaptive Fuzzy Logic Controller with Rule Based Changeable Universe of Discourse for a Nonlinear MIMO System," in 5th International Conference on Intelligent Systems Design and Applications, 2005, pp. 8-13.

[10] Z. Ibrahim and E. Levi, "A Comparative Analysis of Fuzzy Logic and PI Speed Control in High Performance AC Drives using Experimental Approach," IEEE Transactions on Industry Applications, vol. 38, no. 38, pp. 1210-1218, Sep./Oct. 2002.

https://doi.org/10.1109/TIA.2002.802993

[11] M. N. Uddin, T. S. Radwan, and M. Azizur Rahman, "Performances of Fuzzy Logic Based Indirect Vector Control for Induction Motor Drive," IEEE Transactions on Industry Applications, vol. 38, no. 38, pp. 1219-1225, Sep./Oct. 2002. https://doi.org/10.1109/TIA.2002.802990 
[12] R. Gunabalan and V. Subbiah, "Speed Sensorless Vector Control of Induction Motor Drive with PI and Fuzzy Controller," International Journal of Power Electronics and Drive Systems, vol. 5, no. 5, p. 315, 2015.

https://doi.org/10.11591/ijpeds.v5.i3.pp315-325

[13] S. Rafa, A. Larabi, L. Barazane, M. Manceur, N. Essounbouli, and A. Hamzaoui, "Implementation of a new fuzzy vector control of induction motor," ISA Transactions, vol. 53, no. 53, pp. 744-754, 2014/05/01/2014.

[14] A. Karakaya and E. Karakas, "Performance analysis of PM synchronous motors using fuzzy logic and self tuning fuzzy PI speed controls," Arabian Journal for Science and Engineering, vol. 33, no. 33, pp. 153-177, 2008.

[15] F. Betin, A. Sivert, A. Yazidi, and G. A. Capolino, "Determination of Scaling Factors for Fuzzy Logic Control Using the Sliding-Mode Approach: Application to Control of a DC Machine Drive," IEEE Transactions on Industrial Electronics, vol. 54, no. 54, pp. 296-309, Feb. 2007.

https://doi.org/10.1109/TIE.2006.885506

[16] C. Ming, S. Qiang, and E. Zhou, "New Self Tuning Fuzzy PI Control of a Novel Doubly Salient Permanent Magnet Motor Drive," IEEE Transactions on Industrial Electronics, vol. 53, no. 53, pp. 814-821, 2006.

https://doi.org/10.1109/TIE.2006.874269

[17] M. H. N. Talib, Z. Ibrahim, N. A. Rahim, and A. S. A. Hasim, "Comparison Analysis of Indirect FOC Induction Motor Drive using PI, Anti-Windup and Pre Filter Schemes," International Journal of Power Electronics and Drive Systems (IJPEDS), vol. 4, no. 4, pp. 219-229, 2014.

https://doi.org/10.11591/ijpeds.v4i4.6250

[18] M. H. N. Talib, Z. Ibrahim, N. A. Rahim, and A. S. A. Hasim, "Performance Improvement of Induction Motor Drive Using Simplified FLC Method," in 16th International Power Electronics and Motion Control Conference and Exposition, Antalya, Turkey, 2014, pp. 843-848.

https://doi.org/10.1109/EPEPEMC.2014.6980580 